\title{
The clinical management of a patient with depressive disorder: a case vignette study to examine general practitioners' views
}

\section{AIMS AND METHOD}

The study aimed to examine general practitioner (GP) views about the appropriate management of a patient with a depressive disorder. A questionnaire based around a patient case history was sent to 188 GPs from 11 primary care groups nationally.

\author{
RESULTS \\ The response rate was $62 \%$. At first \\ presentation, a third of GPs offered \\ 'watchful waiting' and a third pre- \\ scribed medication. If the patient's \\ condition deteriorated, nearly all GPs \\ initiated therapeutic doses of anti- \\ depressant medication immediately. \\ If the patient failed to respond, $60 \%$ \\ of GPs commenced second-line anti- \\ depressant treatment. Following \\ recovery, a quarter of GPs would
}

\begin{abstract}
continue antidepressant treatment for 4 months or more.

\section{CLINICAL IMPLICATIONS}

GPs' interventions in the management of depression concur with expert national guidelines. There is scope for strengthening the effectiveness of pharmacological intervention in the later stages of treatment.
\end{abstract}

Depression is very common among patients presenting in primary care. The condition is associated with considerable chronicity (Kessler et al, 1997) and morbidity (Murray et al, 1997), and in the UK $80 \%$ of patients identified as having depression are treated entirely in primary care (Goldberg \& Huxley, 1992). On average, an NHS general practitioner (GP) consultation lasts for less than 10 minutes, and there will be one patient with depression seen during each surgery. A small proportion of these are referred to specialist mental health services. Both antidepressant drugs and specific psychological therapies (cognitive-behavioural therapy (CBT) and interpersonal therapy (IPT)) have been shown to be beneficial in the management of depression (Department of Health, 2001).

The study aimed to examine GPs' views about the appropriate management of a patient diagnosed with depressive illness, their use of medication and their shared management of such a patient with other specialists working either within general practice or in local community or secondary mental health services. This study was one component of the UK-wide Clinical Standards Advisory Group (CSAG) depression study (Clinical Standards Advisory Group, 1999).

\section{The study}

\section{The questionnaire}

A self-administered, structured questionnaire was developed and piloted, based on the case history describing a male patient presenting initially with a 5-week history of a depressive disorder (part one) associated with a single, recent life event (suspension from work). The case history was separated into two further components, which described the patient's deterioration (part two) and recovery from acute symptoms of depression (part three) (see Box 1 for case vignette). For the purpose of data analysis, the patient's condition fulfilled the diagnostic criteria for major depression, in part one with mild psychosocial impairment and in part two with severe psychosocial impairment. Each part was accompanied by a series of closed questions, each with several stems. Space for free text was included where appropriate.

\section{The sample}

The sampling process for the main CSAG study identified 11 geographical areas that were visited by a CSAG review team. An up-to-date list of GPs in each area was requested from each health authority or health board, together with details of proposed primary care groups in the area. The sample included one area from each of the eight NHS regions in England and one each from Northern Ireland, Scotland and Wales. Each area was either a single primary care group (PCG) or, for those places where no PCGs existed, a sample of sites of equivalent size, which were as representative as possible of the range of socio-demographic groups as defined by the Office for National Statistics (ONS, 1996).

\section{Data collection}

Between 12 and 15 general practices (covering the full range of partnership sizes) were selected. Each practice was invited to participate in interviews with the CSAG depression visiting teams. The case history and questionnaire was sent with a covering letter to all GPs $(n=188)$ from the practices that had agreed to participate in the site visits, in advance of the visit. Members of the visiting team collected completed questionnaires at the time of the visit. 


\section{Box 1. Case vignette}

original

papers

\section{Part one}

You have diagnosed depression in a 35-year-old man, who works as an administrator in a local authority sports centre. He lives with his wife and two young children in a nearby council house. He has presented in your surgery complaining of pain in his hip, but during the consultation you notice that he is tearful, and when asked he described feelings of worthlessness.

On enquiry, you elicit the following symptoms: persistent mood of sadness and a tendency to wake up briefly in the middle of the night for the past 5 weeks. His appetite is poorer than usual, although he has not lost weight. He denies early morning waking or diurnal variation of mood. His concentration is not disturbed and he is not lethargic. He denies any suicidal thoughts. There is no past history of self-harm.

He attributes his state of mind to a recent dispute at work, which has resulted in him becoming the subject of a complaint from a colleague, because of his attitude towards her. He was suspended 14 days ago, pending an internal enquiry. He feels lost without his work, but also says he feels he has been done an injustice and is resentful about the way he has been treated. He is finding it extremely difficult to adjust to staying at home all day and is particularly aware of his irritability when around his family, and mentions how guilty this makes him feel.

\section{Part two}

The patient does not come to see you for a further 6 weeks. Since his last contact, he has not taken up any interventions offered, nor has he been seen again in primary or secondary care. The dispute at work has been resolved in his favour, but he feels unable to return there and complains of feeling guilty about what happened. His symptoms have worsened. He wakes early each morning and he feels at his worst then, improving gradually as the day goes on. His appetite remains poor and he has lost some weight. He says he had hoped he could get by without the help offered to him previously, but now he realises he is not coping. He denies suicidal thoughts.

\section{Part three}

The patient returns for a planned review, and explains he has just returned to work. He is coping well and collaborating with the agreed treatment plan. He is tolerating antidepressant drug treatment, and asks if he can now discontinue it since he has felt well for the past 4 weeks. You briefly review his notes and confirm that he has now been taking the course continuously for 3 months.

\section{Results}

\section{Part one}

One hundred and seventeen (62\%) completed questionnaires were returned. At the initial patient consultation 48 GPs (41\%) stated they would offer 'watchful waiting' and 40 (34\%) would prescribe medication immediately, although if the patient stated a clear preference for medication at this stage, this increased to $72(61 \%)$. When a prescription was indicated, an antidepressant was nearly always the treatment of choice ( $n=69 ; 95 \%$ ). Thirteen (11\%) GPs wanted to refer straight away to a specialist and thirteen provided patient information sheets routinely.

\section{Part two}

Ninety-five per cent of GPs stated they wanted to review the patient within 2 weeks, and the median interval to the next follow-up appointment was 2 weeks (range: 1 week to 1 month). If the patient's condition had deteriorated, or failed to respond, when seen 4 weeks after first presentation (part two) all GPs would now prescribe an antidepressant. Half of the sample $(n=58 ; 50 \%)$ chose a selective serotonin reuptake inhibitor (SSRI) as first-line treatment and $41 \%(n=48)$ chose a tricyclic antidepressant (TCA). Once established on antidepressant treatment, most GPs $(n=95 ; 81 \%)$ said they would review the patient within 2 weeks. The mean duration of the trial of highest dose treatment was 5.7 weeks before concluding the treatment was not working. The most commonly selected SSRIs were fluoxetine $(n=31)$, at a median starting dose of $20 \mathrm{mg}$ and median highest dose of $40 \mathrm{mg}$, and paroxetine $(n=16)$ at a median starting dose of $20 \mathrm{mg}$ and median highest dose of $40 \mathrm{mg}$. The most commonly selected TCAs were dothiepin $(n=30)$, at a median starting dose of $75 \mathrm{mg}$ and median highest dose of $150 \mathrm{mg}$, and amitriptyline $(n=9)$ at a median starting dose of $125 \mathrm{mg}$ and median highest dose of $150 \mathrm{mg}$.

If the patient's condition failed to respond adequately to first-line prescribed treatment, 69 GPs (59\%) switched the patient to a second-line antidepressant. At this stage 83 (71\%) said they would also refer to another mental health specialist, either within the primary health care team or in specialist services. Thirty-eight per cent of GPs said that counselling was the most appropriate psychological intervention at this stage, 37\% CBT and 8\% psychodynamic therapy.

\section{Part three}

Once the patient demonstrated a complete recovery, most GPs (74/117; 63.2\%) advised continued antidepressant treatment for at least 3 months, and over a quarter (33; $28 \%$ ) for 4 months or more.

\section{Discussion}

Only a third of GPs said they would initiate a prescription for a patient with a mild disorder presenting for the first time. The two-thirds who would not are in accord with expert guidelines on appropriate management. Evidencebased guidelines recommend TCAs should be the treatment of first choice in the primary care of depression (Eccles et al, 1999), although in this sample SSRIs were most favoured among GPs and there is independent evidence of a rising popularity in the use of SSRIs (Martin et al, 1997). This might reflect the impact of aggressive marketing of SSRIs since the guidelines were introduced, as well as a significant body of opinion that SSRIs are preferable as a first-line treatment. When a trial of firstline antidepressant failed, about two-thirds of GPs switched to a second-line antidepressant. About twothirds of GPs suggested discontinuing treatment within 3 months of complete recovery. Recent expert guidelines suggest the effective dose should be continued for 6 
months following complete resolution of the symptoms of a first episode (Anderson et al, 2000).

Where the patient's condition warranted a specific intervention this was usually antidepressant medication. Antidepressant treatment was often the only treatment of proven efficacy that was offered to those who required more than watchful waiting or non-specific counselling. Nationally, there is evidence of long waitinglists for small numbers of mental health workers with training in specific psychological treatments, usually CBT (CSAG, 1999). There was little evidence to suggest that patients are offered a choice of treatment or interventions to promote concordance and self-management, such as psychoeducation or the use of patient information leaflets.

Studies of this kind depend on interviewees and their self-report rather than more robust methods such as direct observation of consulting behaviour. All responders were self-selected and therefore more likely to be interested in, and knowledgeable of, mental health issues. For these reasons, the results may represent higher than average standards, and reflect aspirations rather than actual practice. The findings reported here suggest GPs' knowledge of the assessment and management of depression, including effective prescribing of first- and second-line antidepressant medication, generally concurs with expert guidelines for effective intervention, although there may be scope for strengthening intervention during the continuation phase and withdrawal of pharmacological treatment. Although patients prefer psychological treatment to drug treatment, and ask for counselling, they usually exercise little choice in the intervention they receive.

\section{Declaration of interest}

None.

original papers

\section{References}

ANDERSON, I. M., NUTT, D. J. \& DEAKING, J. F.W. (2000) Evidence based guidelines for treating depressive disorders with antidepressants: a review of the 1993 British Association for Pharmacology Guidelines. Journal of

Psychopharmacology, 14(1), 3-20.

CLINICAL STANDARDS ADVISORY GROUP (1999) Services for People with Depression. London: Department of Health.

DEPARTMENT OF HEALTH (2001) Treatment Choice in Psychological Therapies and Counselling: Evidence Based Clinical Practice Guideline. London: HMSO

ECCLES, M., FREEMANTLE, N. \& MASON, J. (1999) North of England evidence-based guideline development project: summary version of guidelines for the choice of antidepressants for depression in primary care. Family Practice, 16, 103-111.

GOLDBERG, D. \& HUXLEY, P. (1992) Common Mental Disorders. A BioSocial Model. London: Routledge.

*Sarah Marriott Consultant Psychiatrist, Paterson Centre for Mental Health, 20 South Wharf Road, LondonW2 1EE， Christine Wright CSAG Research Assistant, Paul Lelliott Director, Royal College of Psychiatrists' Research Unit
KESSLER, R. C., ZHAO, S., BLAZER, D. G., et al (1997) Prevalence correlates and course of minor depression and major depression in the national comorbidity survey. Journal of Affective Disorders, 45, 19-30.

MARTIN, R. M., HILTON, S. R., KERRY S. M., et al (1997) General practitioners' perceptions about the tolerability of antidepressant drugs: a comparison between selective serotonin reuptake inhibitors and tricyclics. BMJ, 314 646-651.

MURRAY, C. J. \& LOPEZ, A. D. (1997) Alternate projections of mortality and disability by cause 1999-2020: global burden of disease study. Lancet, $\mathbf{3 4 9}$ 1498-1504.

OFFICE FOR NATIONAL STATISTICS (1996) The ONS Classification of Local and Health Authorities of Great Britain. London: HMSO

\section{The relationship between medical school of training, age, gender and success in the MRCPsych examinations}

\section{AIMS AND METHOD}

Factors leading to success in the MRCPsych Part I and Part II examinations, including age, gender and original medical school of training, were examined in the 1999 MRCPsych examination entrants to determine how far they are associated with the results. The ethnic breakdown of examiners of the MRCPsych examinations was also determined and compared with the origin of all consultant psychiatrists.

\author{
RESULTS \\ Younger age at taking the examina- \\ tion and training at a British or Irish \\ medical school were found to be \\ highly significant predictors of \\ success in the MRCPsych examina- \\ tions. When allowance was made for \\ confounding variables, the gender \\ of candidates did not contribute to \\ success. There was no difference \\ in ethnic background of examiners \\ compared with consultant \\ psychiatrists overall.
}

\author{
CLINICAL IMPLICATIONS \\ Factors affecting trainees wishing to \\ undertake a psychiatric career need \\ to be more closely examined. To \\ ensure fairness and transparency in \\ future examinations the ethnicity of \\ candidates taking the examination \\ needs to be addressed.
}

\section{Introduction}

The Membership examination of the Royal College of Psychiatrists (MRCPsych) is scrutinised regularly by an examinations monitoring panel - a group of senior examiners and educators who are appointed by the College's senior academic committee, the Court of Electors. All parts of the examination are reviewed carefully. 